\title{
Divya-Herbal-Peya Decoction Harmonizes the Inflammatory Response in Lipopolysaccharide-Induced Zebrafish Model
}

\author{
Acharya Balkrishnal-3 \\ Savita Lochab (ID) \\ Monali Joshi ${ }^{5}$ \\ Jyotish Srivastava ${ }^{5}$ \\ Anurag Varshney (1D ${ }^{1,2,6}$ \\ 'Drug Discovery and Development \\ Division, Patanjali Research Institute, \\ Haridwar, 249405, Uttarakhand, India; \\ ${ }^{2}$ Department of Allied and Applied \\ Sciences, University of Patanjali, Patanjali \\ Yog Peeth, Haridwar, 249405, \\ Uttarakhand, India; ${ }^{3}$ Patanjali Yog Peeth \\ (UK) Trust, Glasgow, G4I IAU, UK; \\ ${ }^{4}$ Department of Biology, Drug Discovery \\ and Development Division, Patanjali \\ Research Institute, Haridwar, 249405, \\ Uttarakhand, India; ${ }^{5}$ Department of \\ Chemistry, Drug Discovery and \\ Development Division, Patanjali Research \\ Institute, Haridwar, 249405, Uttarakhand, \\ India; ${ }^{6}$ Special Centre for Systems \\ Medicine, Jawaharlal Nehru University, \\ New Delhi, India
}

Background: Divya-Herbal-Peya (DHP) is a plant-based decoction containing fourteen herbs in precise quantities; usually prescribed by the practitioners in Ayurveda to alleviate stress and minimize the exasperating symptoms of recurring infections. Our study aims to provide an experimental validation to the immunomodulatory properties of DHP.

Methods: Physico-chemical analysis of DHP was performed to evaluate the presence of secondary metabolites. The phytochemicals were then identified and quantitated through HPTLC, UHPLC, and GC-MS techniques. To address the scientific rationale behind DHP, lipopolysaccharide (LPS) was intraperitoneally injected in adult zebrafish to develop inflammatory response. Following LPS-induction, abnormality in locomotory behaviour was determined by evaluating the relative swim velocity and the rate of turning in experimental zebrafish. Pathophysiological effects were determined through opercular frequency, behavioural fever, and caudal fin damage. LPS-mediated inflammation was measured of pro-inflammatory cytokines, TNF $\alpha$, IL- 6 , and IL- $1 \beta$ expression in the serum of study animals, by RT-PCR.

Results: Our study phytochemically characterized and ascertained the presence of glycyrrhizin, rosmarinic acid, gingerol, cinnamic acid, protocatechuic acid, gallic acid, ellagic acid, piperine and cinnamaldehyde in DHP decoction. LPS induced aberrant locomotory patterns, behavioural fever and caudal fin damage in zebrafish. A significant increase in gene expression levels of pro-inflammatory cytokines, TNF $\alpha$, IL- 6 , and IL-1 $\beta$ was also determined. However, these locomotory deviations and behavioural fever were negligible in zebrafish groups preadministered either with DHP in a dose dependent manner or dexamethasone (DEX). The altered opercular rate, caudal fin damage and elevated transcription levels of pro-inflammatory genes upon LPS-induction were averted in groups pre-treated with DHP and DEX.

Conclusion: DHP prophylactically prevented the LPS-induced abnormal behaviour and inflammation-related pathophysiology in zebrafish. Immunomodulatory properties of DHP may not have therapeutic intervention, but do confer nutraceutical health benefits against mild infections.

Keywords: immunomodulatory, anti-inflammatory, zebrafish, phytometabolites, DivyaHerbal-Peya, herbal decoction

\section{Introduction}

Ayurveda, a traditional form of medicine has been practiced in India for centuries and has contributed notably to the health maintenance system. It encourages the adaption of specific herbs, either crude or in the form of decoctions to circumvent recurrent infections. ${ }^{1,2}$ However, limited scientific evidence on their safety, efficacy, and mechanism of action has fostered enigmas in the mainstream health care
Correspondence: Anurag Varshney Drug Discovery and Development Division, Patanjali Research Institute, NH-58, Haridwar, 249405, Uttarakhand, India Email anurag@prft.co.in 


\section{Graphical Abstract}

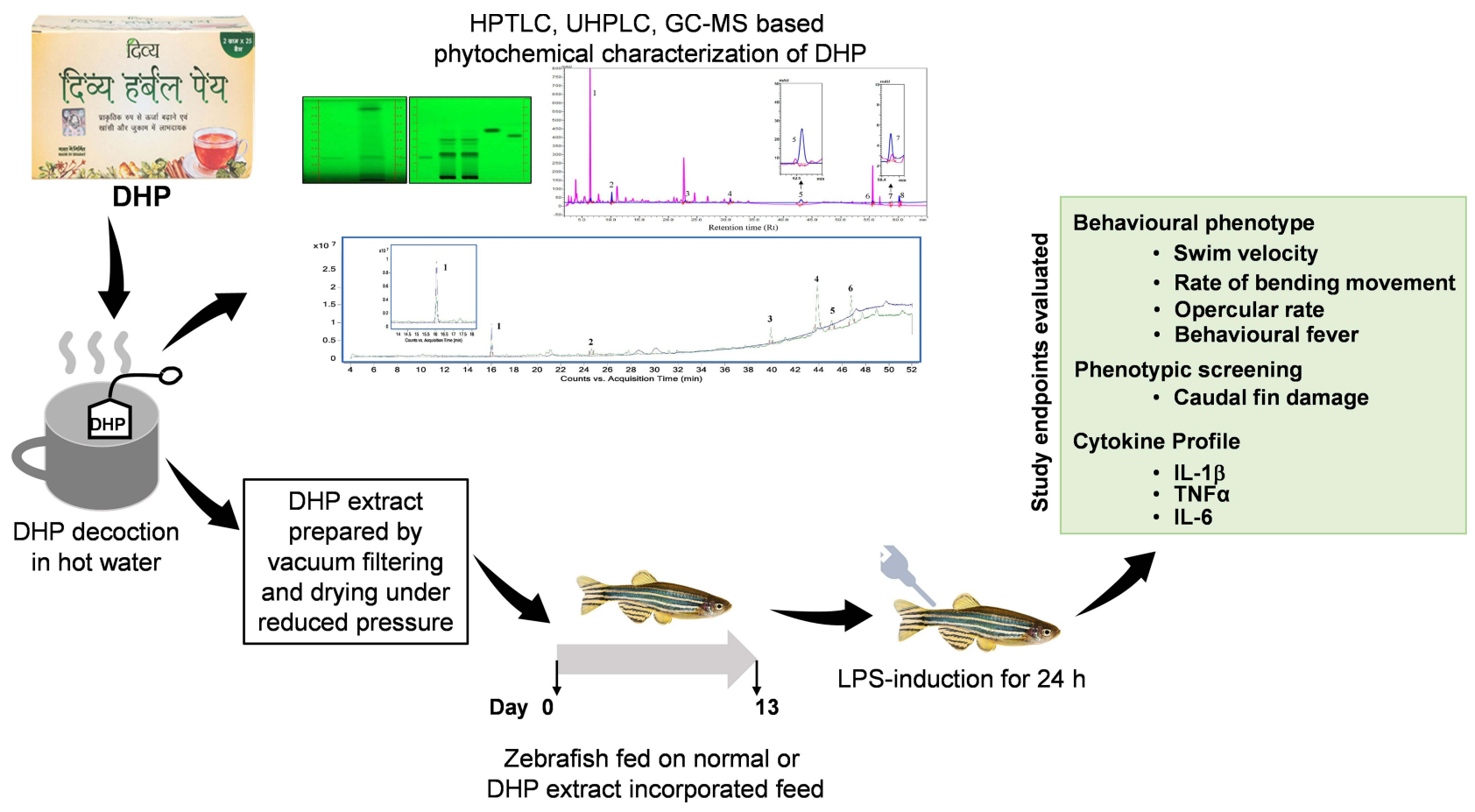

system. Along similar lines, Divya-Herbal-Peya (henceforth, DHP) is an example of a herbal decoction that contains multiple herbs in precise quantities. It is prescribed by Ayurveda to alleviate stress and minimize the exasperating symptoms of fever, cold, and cough. Considering the benefits of DHP, it is imperative to dissect the scientific rationale, albeit, experimentally behind this evidence-based herbal drink. We aimed to validate the nutraceutical property of DHP that prevent infections and mitigate the associated symptoms.

The composition of DHP follows the concept of "polyherbalism" to have extra therapeutic effectiveness compared to a single herb. ${ }^{3}$ It contains herbs that exhibit anti-microbial and anti-inflammatory properties. These herbs are a rich source of natural polyphenols, flavonoids, saponins, tannin and essential oils with therapeutic potentials. A thorough compositional analysis prompted us to determine the probable immunomodulatory properties that enabled it to subside symptoms related to mild infections, cough, or fever. To test our hypothesis, we first chemically characterized DHP through high-performance thin liquid chromatography (HPTLC), ultra-high-performance liquid chromatography (UHPLC) and gas chromatography-mass spectrometry (GC-MS) techniques and determined the presence of phytometabolites namely, glycyrrhizin, rosmarinic acid, gingerol, cinnamic acid, protocatechuic acid, gallic acid, ellagic acid, piperine and cinnamaldehyde. The identified phytometabolites have demonstrated anti-inflammatory and anti-microbial properties.

Our study further explored the prophylactic role of DHP in combating the inflammatory response during infection. We developed the inflammatory model system by inducing zebrafish (Danio rerio) with lipopolysaccharide (LPS). Zebrafish show congruity with mammals in terms of physiological signalling pathways and functions. ${ }^{4}$ Zebrafish is an established model to study immunology in humans associated with pathogenesis of bacterial and viral infections. ${ }^{5}$ Previously, lipopolysaccharide (LPS)-induced adult zebrafish has been demonstrated as an in vivo model of inflammation for pharmacological studies. ${ }^{6,7}$

We, therefore, assessed the immunomodulatory impact of DHP on LPS mediated inflammatory response in zebrafish. LPS induction resulted in behavioural sickness and aberrant locomotory patterns in zebrafish. However, zebrafish pre-administered with DHP maintained the normal behavioural and locomotory patterns. We demonstrate that DHP significantly normalized the LPS-inflicted aberrant locomotory patterns in zebrafish model. DHP also 
attuned the intensified opercular rate and behavioural fever in LPS stimulated zebrafish model. Phenotypic screening showed that DHP counterplayed the LPS effectuated damaged caudal fin of zebrafish. Furthermore, we addressed the anti-inflammatory activity of DHP by assessing the gene expression levels of inflammatory markers, namely, CRP, TNF $\alpha$, IL-6 and IL-1 $\beta$ in LPS-challenged zebrafish. Taken together, our study presents experimental evidences showing DHP as a plant-derived immunomodulatory drink.

\section{Materials and Methods}

\section{Chemicals and Reagents}

We sourced DHP (Batch \# B-DHP109, with expiry in May 2022) from the manufacturer, Divya Pharmacy, Haridwar, India. Lipopolysaccharides from Escherichia coli O111:B4 (L2630) and dexamethasone (PHR1526) were procured from Sigma-Aldrich, Bangalore. Standards for HPTLC, UHPLC and GC-MS were purchased from Natural Remedies Private Ltd., Bangalore; Sigma Aldrich, Bangalore; Cayman chemicals, USA; SISCO Research Lab (SRL), India. HPLC-grade chemicals were majorly procured from Merck and Sigma Aldrich.

\section{Evaluation of Physico-Chemical Properties of DHP}

DHP is commercially available as dried powder packed in a filter paper bag similar to that of tea bags. $2 \mathrm{~g}$ DHP in each bag is packed to simplify the decoction preparation in terms of ease and efforts. These bags being porous helps in proper extraction of phytometabolites of DHP in hot water. Water decoction yield of $5.5 \mathrm{~g}$ of DHP sample was evaluated by boiling it in water for $120 \mathrm{~min}$. The extract was then vacuumfiltered and dried under reduced pressure. The obtained residue was weighted to calculate the percentage of water decoction yield according to the following formula:

Percentage of water decoction yield $=$ (Weight of obtained residue/Weight of sample) $\times 100$.

The purity of DHP was determined by calculating the total ash value and acid insoluble ash value. Dried DHP was incinerated in a crucible at $600^{\circ} \mathrm{C}$ for $3-4 \mathrm{~h}$ to obtain a carbon free ash which was weighed to calculate total ash content as a percentage considering the starting quantity as reference. Total ash was then heated in $25 \mathrm{~mL}$ of $5 \mathrm{~N} \mathrm{HCl}$ for $10 \mathrm{~min}$ and filtered. The filtrate was returned back to a muffle furnace in the crucible after several washes with water. The residue obtained was allowed to cool in a desiccator for $30 \mathrm{~min}$ and weighted to determine insoluble ash value.

\section{Quantitative Estimation of Phytometabolites in DHP}

The Folin Ciocalteu method was employed to determine the total phenol content in DHP. ${ }^{8,9}$ The calibration curve generated from gallic acid served as the standard to calculate the total phenolic content in gallic acid equivalents (GAE) per mg dry weight of DHP. ${ }^{10}$ Flavonoids were quantified using aluminium chloride method of extraction described previously. The calibration curve of quercetin was generated to calculate total flavonoid content in quercetin equivalents (QE) per mg dry weight of DHP. Saponins were estimated by adding vanillin-ethanol (2 $\mathrm{mL}, 8 \% \mathrm{w} / \mathrm{v}$ ) and $75 \%$ sulphuric acid to aqueous extracts of DHP. The mixture was then incubated at $60{ }^{\circ} \mathrm{C}$ for 10 min before recording absorbance at $544 \mathrm{~nm}$. Saponin content was determined against the absorbance standard curve generated for diosgenin. For tannin quantification, the aqueous extract of DHP was titrated against the $0.1 \mathrm{~N}$ potassium permanganate solution. Proanthocynadine estimation was done by adding $4 \%$ vallinin-methanol and hydrochloric acid to aqueous extract of DHP. This mixture was then incubated at room temperature for $15 \mathrm{~min}$ before recording absorbance at $500 \mathrm{~nm}$. Proanthocynadine content was evaluated against catechin standard. ${ }^{11}$

\section{High-Performance Thin Liquid Chromatography (HPTLC) Analysis}

HPTLC system (Camag, Switzerland) appendaged with an automated TLC sampler (ATS4) and scanner 4 was deployed for the identification of phytochemicals in DHP. Analysis was carried out using integrated software, Win-CATS. $350 \mathrm{mg}$ of DHP was dissolved in $6 \mathrm{~mL}$ of water: methanol (9: 1) followed by sonication and centrifugation to obtain a clear solution. Separation of this solution was performed on precoated silica gel 60F254 plates. The phytoconstituents in DHP sample were identified and quantified by equating the $\mathrm{Rf}$ values of observed bands with the $\mathrm{Rf}$ values of standards. Mobile phase-A (toluene: ethyl acetate: formic acid (9: 10: $1 \mathrm{v} / \mathrm{v} / \mathrm{v})$ ) was used to separate rosmarinic acid (RA), piperine (PE) and cinnamic acid (CA) while, mobile phase-B (ethyl acetate: formic acid: acetic acid: water (10: 1: 1: $2.3 \mathrm{v} / \mathrm{v} / \mathrm{v})$ ) was used to detect glycyrrhizin (GA). TLC plates were air dried and scanned at wavelengths of $254 \mathrm{~nm}$ for visualizing bands and $280 \mathrm{~nm}$ for 
generating 3-D overlay desitograms. Standards used in HPTLC were the same as briefed in UHPLC.

\section{Ultra-High-Performance Liquid Chromatography (UHPLC) Analysis}

DHP was analysed for the presence of signature phytometabolites by UHPLC (Shimadzu Prominence XR, Japan) armed with a quaternary pump (Nexera XR LC-20AD XR) comprising of degassing unit (DGU-20A 5R), DAD detector (SPDM20 A) and auto-sampler (Nexera XR SIL-20 AC XR).

$0.5 \mathrm{~g}$ DHP was diluted with $10 \mathrm{~mL}$ of methanol:water (10:90) and sonicated for $30 \mathrm{~min}$. The sample was then centrifuged at high speed and filtered using $0.45 \mu$ nylon filter before injecting into the HPLC unit. Standards include markers for gallic acid (potency - 97.30\%, Sigma Aldrich), protocatechuic acid (potency - 99.50\%, Natural Remedies), glycyrrhizin (potency - 93.0\%, Natural Remedies), ellagic acid (potency - 99.60\%, Sigma Aldrich), rosmarinic acid (potency - 98.0\%, Sigma Aldrich), cinnamic acid (potency - 99.70\%, SRL), 6-gingerol (potency - 98.90\%, Cayman Chemicals) and piperine (potency - 97.0\%, Sigma Aldrich). $10 \mu \mathrm{L}$ of each of DHP sample and standards were independently injected in Shodex C18-4E $(5 \mu \mathrm{m}, 4.6 \times 250 \mathrm{~mm})$ column to acquire appropriate separation of constituents through binary gradient elution. Solvent A $(0.1 \%$ orthophosphoric acid in water, adjusted at $\mathrm{pH} 2.5$ with diethylamine) and solvent B (acetonitrile). Gradient was achieved by following a course of mixing solvent $B$ to $A$ in a specific ratio of 5-15\% for 0-10 $\mathrm{min}, 15-20 \%$ for $10-20 \mathrm{~min}, 20-25 \%$ for 20-30 min, $25 \%$ for $30-40 \mathrm{~min}, 25-40 \%$ for $40-50 \mathrm{~min}$, $40-70 \%$ for $50-60 \mathrm{~min}, 70-90 \%$ for $60-65 \mathrm{~min}, 90-95 \%$ for $65-60 \mathrm{~min}$ and $95 \%$ for $66-70 \mathrm{~min}$. Flow rate of $1.0 \mathrm{~mL} / \mathrm{min}$ for all samples was maintained in the column at $35^{\circ} \mathrm{C}$. The peaks in the chromatogram were recorded at $250 \mathrm{~nm}$. Phytoconstituents in DHP were identified on the basis of retention time with reference to that of standards.

\section{Phytochemical Identification and Quantification by Gas Chromatography- Mass Spectrometry (GC-MS)}

For identifying phytoconstituents in DHP, hexane extract of the same was prepared by incubating $106 \mathrm{mg}$ of DHP sample in $5.0 \mathrm{~mL}$ of hexane followed by centrifugation at high speed and filter through $0.22 \mu$ nylon filter. Stock solution of cinnamaldehyde (potency - 99.5\%, Sigma Aldrich) was prepared by dissolving $32.3 \mathrm{mg}$ in $25 \mathrm{~mL}$ of methanol, which was further diluted 10 times in methanol. Analysis was performed on 7000D GC/MS triple quad with 7890B GC system (Agilent, USA) facilitated with mass hunter software. HP-INNOWAX capillary column $(30 \mathrm{~m} \times 0.25 \mathrm{~mm}, 0.25$ $\mu \mathrm{m})$ was utilized for separating the DHP sample and standard. The carrier gas (helium) flow rate was maintained at 1 $\mathrm{mL} / \mathrm{min}$. The injection volume was $1 \mu \mathrm{L}$ for DHP sample and the temperature of the split injector was regulated at $250{ }^{\circ} \mathrm{C}$ and the split ratio was $20: 1$. The column temperature was set at $80{ }^{\circ} \mathrm{C}$ (hold $2 \mathrm{~min}$ ) and then programmed at $10{ }^{\circ} \mathrm{C} / \mathrm{min}$ to $160{ }^{\circ} \mathrm{C}$ (hold $3 \mathrm{~min}$ ), followed by $2{ }^{\circ} \mathrm{C} / \mathrm{min}$ to $230^{\circ} \mathrm{C}$ (hold 4 $\mathrm{min})$. The $\mathrm{GC}-\mathrm{MS}$ ion source temperature and ionization potential was set at $230{ }^{\circ} \mathrm{C}$ and $70 \mathrm{eV}$, respectively. The compounds identified were taken from NIST14.L library.

The quantification of cinnamaldehyde was performed using response factor of reference standard whereas other molecules where quantified considering the area \% obtained in the chromatogram taking cinnamaldehyde content as internal standard and applying the molecular weight correction factor of individual molecules.

\section{Zebrafish Maintenance}

Wild type $\mathrm{AB}$ strain zebrafish of irrespective gender, comparable weight $(0.5 \mathrm{~g})$ and age (1.2-1.5 years) were sourced from Pentagrit in-house breeding facility. We randomly assigned 24 adult zebrafish in each group. Zebrafish were maintained at 14 h:10 h (light: dark) cycle at $27 \pm 1{ }^{\circ} \mathrm{C}$. Water quality and housing units were maintained as per standard protocols. Zebrafish were fed everyday with $5 \mathrm{mg}$ per gram body weight of commercial feed (TetraBit, Spectrum Brands Pet LLC, Blacksburg, VA, USA). Fish were euthanized through rapid cooling method discussed previously. ${ }^{12}$

\section{Dosing Regimen in Zebrafish}

The DHP dose for zebrafish model was optimized to be 1000 times lesser than the human equivalent dose based on the relative body weight and surface area of zebrafish. Accordingly, the human equivalent dose of DHP (2 g/day; $26.6 \mathrm{mg} / \mathrm{kg}$ ) was translated to $28 \mu \mathrm{g} / \mathrm{kg}$ for zebrafish. Similarly, human prescribed dose of dexamethasone (DEX) is $6 \mathrm{mg} / \mathrm{day}(100 \mu \mathrm{g} / \mathrm{kg})$ that was translated to $0.08 \mu \mathrm{g} / \mathrm{kg}$ for zebrafish. ${ }^{13}$ After acclimatizing zebrafish in standard laboratory conditions for seven days, they were divided into six groups (Groups I-VI) of 24 fish each. At day 0, Group I and Group II were fed with the normal fish feed whereas Group III was fed with feed comprising of DEX at a dosage of $0.08 \mu \mathrm{g} /$ $\mathrm{kg}$. Group IV, V and VI were fed with fish feed infused with DHP at a dosage of $6 \mu \mathrm{g} / \mathrm{kg}(0.2 \times), 28 \mu \mathrm{g} / \mathrm{kg}(1 \times)$ and $142 \mu \mathrm{g} /$ 
$\operatorname{kg}(5 \times)$, respectively. For 14 days, fish were fed with their respective feed once in $24 \mathrm{~h}$ (Table 1, Figure 1).

\section{LPS-Induction in Zebrafish}

On day 13, except group I (normal control), all groups were induced with LPS. The zebrafish were anesthetized individually using gradual cold-water treatment for that purpose. At first plash fish was placed in water at $17{ }^{\circ} \mathrm{C}$ till the operculum movement minimizes drastically. Zebrafish was then transferred to water at $12{ }^{\circ} \mathrm{C}$ until an evident loss of response towards caudal fin touch was noticed; soon after that zebrafish was placed on injection stage for LPS injection. LPS was prepared in $1 \%$ saline to make a final concentration of $3.33 \mu \mathrm{g} / \mu \mathrm{L} .3 \mu \mathrm{L}$ of LPS solution was injected intraperitoneally in between lateral line and anal pore of all zebrafish of Group II-VI using a Hamilton syringe. Similarly, zebrafish of normal control, Group-I were injected with $3 \mu \mathrm{L}$ of $1 \%$ saline. Immediately after injection, zebrafish were transferred back to recovery tank containing water at $28{ }^{\circ} \mathrm{C} .24 \mathrm{~h}$ post LPS induction or saline injection, zebrafish were analysed for various behavioural and pathological parameters.
Table I Zebrafish Experimental Group Setting and Respective Dosing Regimen

\begin{tabular}{|l|c|c|c|}
\hline $\begin{array}{l}\text { Group } \\
\text { No. }\end{array}$ & $\begin{array}{c}\text { Prophylactic } \\
\text { Exposure }\end{array}$ & Dosage & $\begin{array}{c}\text { LPS- } \\
\text { Induction }\end{array}$ \\
\hline I & None (Control) & - & - \\
II & None & - & + \\
III & DEX & $0.08 \mu g / \mathrm{kg} /$ day & + \\
IV & DHP & $6 \mu g / \mathrm{kg} /$ day $\left(0.2 X^{\#}\right)$ & + \\
V & DHP & $28 \mu g / \mathrm{kg} /$ day $\left(I X^{\#}\right)$ & + \\
VI & DHP & $142 \mu g / \mathrm{kg} /$ day $\left(5 X^{\#}\right)$ & + \\
\hline
\end{tabular}

Note: ${ }^{\#}(X)$ is human equivalent dose.

Abbreviations: DEX, dexamethasone; DHP, Divya-Herbal-Peya.

\section{Evaluation of Zebrafish for Swim Velocity, Turning Rate and Opercular Frequency Rate}

The control and treated zebrafish were placed in adjacent experimental tanks and allowed to acclimatize for $3 \mathrm{~min}$ before being evaluated for motor activities. The experiments were performed at the same time to nullify the circadian biasness among subjects. Swim velocity $(\mathrm{mm} /$ sec) was calculated for individual zebrafish by recording the endpoints of displacement in specific time (sec). Average swim velocity for the whole group was calculated

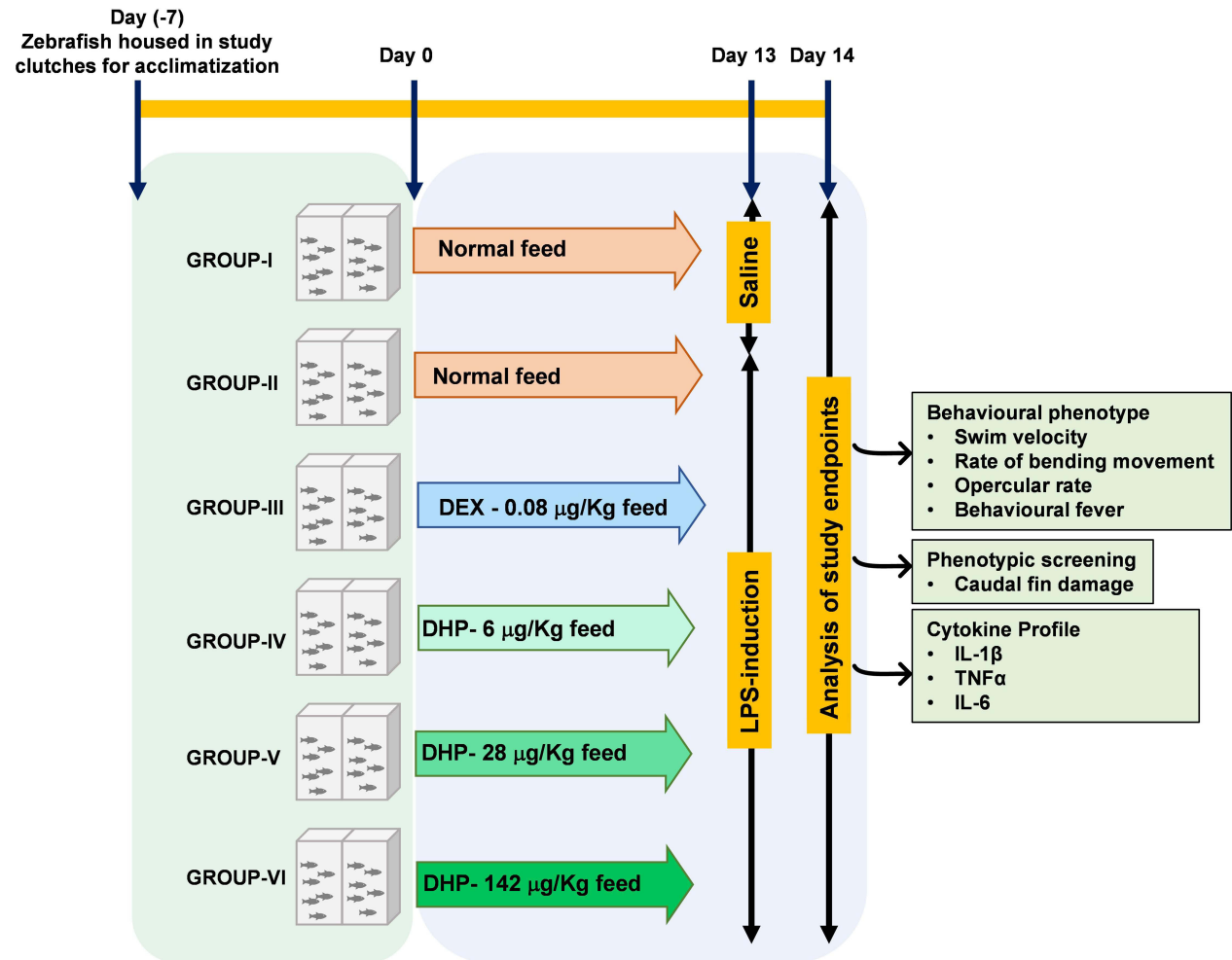

Figure I Schematic representation of experimental design. Zebrafish were divided into six groups (Group I-VI) of 24 fish each and acclimatized for 7 days under standard laboratory conditions. Starting from Day 0 till Day I3, Group I-VI were fed as indicated. DEX and DHP were incorporated in the commercial feed at indicated doses. On day 13, zebrafish were anesthetized for injecting either $10 \mu \mathrm{g}$ LPS or I\% saline. Post $24 \mathrm{~h}$, after injection and returning to their respective recovery tanks, zebrafish were analyzed for indicated clinical endpoints.

Abbreviations: DEX, dexamethasone; DHP, Divya-Herbal-Peya. 
thereafter. Number of turns per min was calculated by counting number of times a zebrafish changes direction of swim in $3 \mathrm{~min}$ consecutively. Similarly, operculum movement was recorded for $3 \mathrm{~min}$ consecutively once the temperamental movements of the zebrafish cease. The data was analyzed from the videos recorded in DSLR camera for $3 \mathrm{~min}$, after acclimatization for all the individual zebrafish. Image J software-based method was followed for evaluating the motor activities. ${ }^{14}$

\section{Assessment of Behavioural Fever in Zebrafish}

Behavioural fever in zebrafish was determined as described earlier. ${ }^{15}$ Briefly, the experimental glass tank with interconnected chambers were used to study behavioural fever in zebrafish. These perforated, interconnected chambers were maintained at $23^{\circ} \mathrm{C}, 29^{\circ} \mathrm{C}$ and $37^{\circ} \mathrm{C}$ with the help of adjacent tanks which were regulated at $18{ }^{\circ} \mathrm{C}$ (low) and $40{ }^{\circ} \mathrm{C}$ (high) with continuous heating or cooling. Each zebrafish from respective groups were introduced individually in the interconnected chambers, allowed to acclimatize for $3 \mathrm{~min}$ and then time spent by them at each temperature was recorded for $3 \mathrm{~min}$ consecutively.

\section{Phenotypic Examination of Caudal Fin Damage}

At the experimental endpoint, zebrafish were monitored carefully for caudal fin damage. Caudal fin was extracted and mounted in PBS before observation under microscope. Images of the caudal fin anatomy were captured using stereomicroscope at $10 \times$ magnification armed with 14MP Labomed camera.

\section{RNA Extraction and RT-PCR}

Total RNA was extracted from fresh fin tissue of zebrafish. Forward and reverse primers were designed with respect to the target gene sequence using Primer-BLAST tool. ${ }^{16}$ Primers used in this study were synthesized from Sigma Aldrich and are briefed in Table 2. Total RNA was isolated using RNAqueous ${ }^{\circledR}$-Micro Kit (Thermo Fisher Scientific, Massachusetts, USA) and reverse transcribed with Transcriptor First Strand cDNA Synthesis Kit (Roche) according to the prescribed guidelines and protocols from the manufacturer. RT-PCR was performed to study the relative quantification of mRNA expression levels of TNF $\alpha$, IL-6, IL$1 \beta$ and were normalized with respect to GAPDH.

\section{Statistical Analysis}

GraphPad Prism 7.0 software and MS office Excel 2010 was used to execute statistical calculations. Data sets of each group are expressed as mean \pm standard error of mean (SEM). p-values for the data sets were considered significant if $\mathrm{p}<0.05\left({ }^{*} \mathrm{p}<0.05,{ }^{* *} \mathrm{p}<0.005,{ }^{* * *} \mathrm{p}<0.0005\right)$ and not significant (ns) if $p>0.05$. To determine the p-values, analysis of the mean values was performed through one-way or two-way analysis of variance (ANOVA) with Dunnett's multiple comparison test.

\section{Animal Ethics}

All the experimental procedures and protocols with respect to zebrafish (Danio rerio) were approved by the Institutional Animal Ethics Committee (IAEC approval number- 226/ Go072020/IAEC) and were followed according to the guidelines of Committee for the Purpose of Control and Supervision of Experiments on Animals (CPCSEA), Government of India; and were in compliance with ICH harmonized principles for animal housing and handling.

\section{Results}

\section{Compositional and Physico-Chemical Analysis Unveiled DHP as a Rich Source of Secondary Metabolites}

We traversed through the plant families and their respective parts which were used to formulate DHP. $44 \%$ of the herbs present in DHP belong to Zingiberaceae and Leguminosease families, while $33 \%$ of them belong to Lauraceae, Poaceae and Lamiaceae families (Figure 2A, Table 3). Moreover, specific part of the plants was selected to prepare a coarse powder of DHP (Figure 2B, Table 3) to yield $38.18 \mathrm{w} / \mathrm{w}$ of water decoction percentage carrying $\mathrm{pH}$ value of 5.08 . We determined $12.59 \% \mathrm{w} / \mathrm{w}$ of total ash and $0.04 \% \mathrm{w} / \mathrm{w}$ of acid insoluble ash that indicated negligible inorganic and silicate impurities in DHP. ${ }^{17}$ Furthermore, we performed various calorimetric tests to evaluate the presence of phytometabolites in DHP. Quantitative analysis against their respective standards unveiled the presence of a significant quantity of polyphenols $(10.71 \% \mathrm{w} / \mathrm{w})$, proanthocynadine $(2.76 \% \mathrm{w} / \mathrm{w})$, flavonoids $(1.23 \% \mathrm{w} / \mathrm{w})$, saponins $(8.13 \% \mathrm{w} / \mathrm{w})$ and tannin $(8.66 \% \mathrm{w} / \mathrm{w})$ (Figure $2 \mathrm{C})$. We also assessed that DHP sample was not contaminated with harmful pathogens, heavy metals or aflatoxins (Table S1). Taken together, we propose that DHP is a scientific combination of herbs that are rich sources of metabolites. 
Table 2 Primer Sequences for RT-PCR

\begin{tabular}{|l|l|l|}
\hline $\begin{array}{l}\text { S. } \\
\text { No. }\end{array}$ & Gene & Sequence \\
\hline 1 & IL-6 & $\begin{array}{l}\text { Fwd: 5'- AGCGTCTTCACCGAAGTCTG-3' } \\
\text { Rev: 5'- GGTTGGTTGGAGGATCCAGG-3' }\end{array}$ \\
\hline 2 & $\begin{array}{l}\text { C Reactive } \\
\text { Protein (CRP) }\end{array}$ & $\begin{array}{l}\text { Fwd: 5'- AAAACCTGCTGAATCGGACT -3' } \\
\text { Rev: 5'- ACTTCGGTAGCCGCTAATGT -3' }\end{array}$ \\
\hline 3 & TNF $\alpha$ & $\begin{array}{l}\text { Fwd: 5'- ACCAGGCCTTTTCTTCAGGT -3' } \\
\text { Rev: 5'- GCATGGCTCATAAGCACTTGTT -3' }\end{array}$ \\
\hline 4 & IL-I $\beta$ & $\begin{array}{l}\text { Fwd: 5'- TTCCCCAAGTGCTGCTTATT -3' } \\
\text { Rev: 5'- AAGTTAAAACCGCTGTGGTCA -3' }\end{array}$ \\
\hline 5 & GAPDH & $\begin{array}{l}\text { Fwd: 5'- GTGTAGGCGTGGACTGTGGT -3' } \\
\text { Rev: 5'- TGGGAGTCAACCAGGACAAATA -3' }\end{array}$ \\
\hline
\end{tabular}

\section{HPTLC, UHPLC and GC-MS Based Identification and Quantification of the Phytochemicals Present in DHP}

We identified and quantified the phytoconstituents in DHP through HPTLC and UHPLC-based methods while volatile components were identified and quantified through GC-MSbased analysis. DHP extracts separated on TLC plates were exposed at $254 \mathrm{~nm}$ to identify phytochemicals with reference to $\mathrm{Rf}$ values of the standards. TLC plate depicted that mobile phase (A) facilitated the separation of rosmarinic acid (RA), cinnamic acid (CA) and piperine (PE) with Rf values of 0.27 , 0.62 and 0.55 , respectively, whereas, mobile phase (B) enabled the separation of glycyrrhizin (GA) with Rf values of 0.27 (Figure 3A). TLC plate analysis at different wavelengths enabled quantification of identified phytochemicals (Figure 3B). Additionally, a 3-D overlay densitogram at 280 $\mathrm{nm}$ was also generated to further substantiate the presence of RA, CA, PE, and GA in DHP (Figure 3C and D). UHPLC chromatograms for DHP extract and standard mix were generated at $250 \mathrm{~nm}$ and subsequently overlayed to identify and quantify phytometabolites (Figure 3E). Chromatograms indicated the presence of significant amounts of gallic acid (24.46 $\mu \mathrm{g} / \mathrm{mg})$, protocatechuic acid $(0.24 \mu \mathrm{g} / \mathrm{mg})$, ellagic acid $(4.02 \mu \mathrm{g} / \mathrm{mg})$, rosmarinic acid $(0.65 \mu \mathrm{g} / \mathrm{mg})$, cinnamic acid $(0.11 \mu \mathrm{g} / \mathrm{mg})$, glycyrrhizin $(2.93 \mu \mathrm{g} / \mathrm{mg})$, 6-gingerol $(0.39 \mu \mathrm{g} / \mathrm{mg})$ and piperine $(0.03 \mu \mathrm{g} / \mathrm{mg})$ in DHP (Figure 3F, Table 4). Moreover, hexane extract of DHP when analysed through GC-MS depicted the presence of cinnamaldehyde, widdrol, gingerol, n-hexadecanoic acid, octaethylene glycol monododecyl ether and octaethylene glycol (Figure 3G, Table 5). Quantification of cinnamaldehyde was performed with respect to the standard.

\section{Pre-Administration of DHP Normalized LPS-Stimulated Aberrant Behavioural Activities in Zebrafish Model}

We assessed modulations in locomotor activity of zebrafish by calculating the average swim velocity $(\mathrm{mm} / \mathrm{sec})$ and turning rate for each test group. LPS challenge significantly reduced the swim velocity indicating impairment in locomotor activity of zebrafish. However, zebrafish pre-treated with DHP demonstrated dose dependent recovery in average swim velocity. DEX administered zebrafish showed similar results as DHP. DHP pre-treatment at the highest dose, indeed, significantly revoked the swim velocity perturbations as the differences between for the same in NC and DHP (142 $\mu \mathrm{g} / \mathrm{kg}$ ) treated groups is statistically non-significant (Figure 4A, Supplementary Figure 1S).

In addition to velocity, turning rate of the zebrafish was also evaluated. LPS induction drastically reduced the turning rate in zebrafish, whereas, zebrafish pre-administered with either DEX or DHP $(142 \mu \mathrm{g} / \mathrm{kg})$ showed negligible reduction (Figure 4B, Supplementary Figure 1S). Dose dependent impact of DHP corroborates the specificity of the herbal formulation towards revival of the body locomotor activity in LPS-treated zebrafish. LPS administration triggered several systemic inflammatory cascades which evoke manifestations in respiratory physiology. ${ }^{18}$ In zebrafish, operculum movement represents the respiratory physiology. A higher opercular beat was observed upon LPS-induction, while DEX or DHP-pre-administered groups showed no anomaly in the opercular beat frequency. Indeed, with increasing dose for DHP a concomitant alleviation in opercular beat frequency was observed (Figure 4C, Supplementary Figure 1S). Together, the data signifies that zebrafish fed with a regular DHP dose substantially retarded the LPS mediated behavioural abnormalities.

\section{Zebrafish Model Pre-Treated with DHP Were Impervious to LPS-Stimulated Behavioural Fever}

Behavioural fever is an important parameter to address the activation of immune response in zebrafish. ${ }^{19}$ We determined that the average time spent by zebrafish injected with LPS was 
A

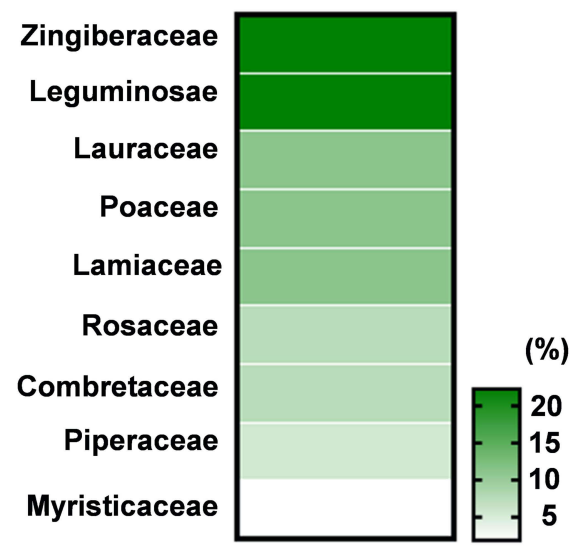

B

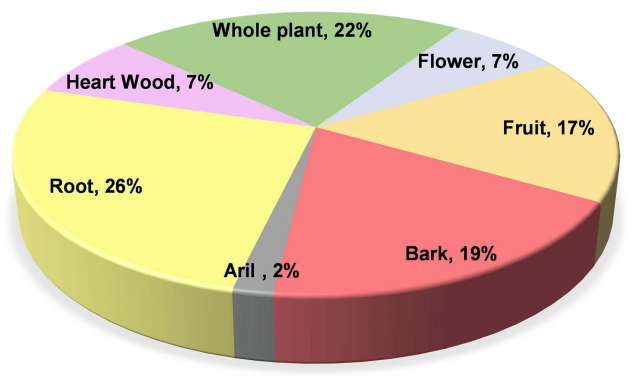

C

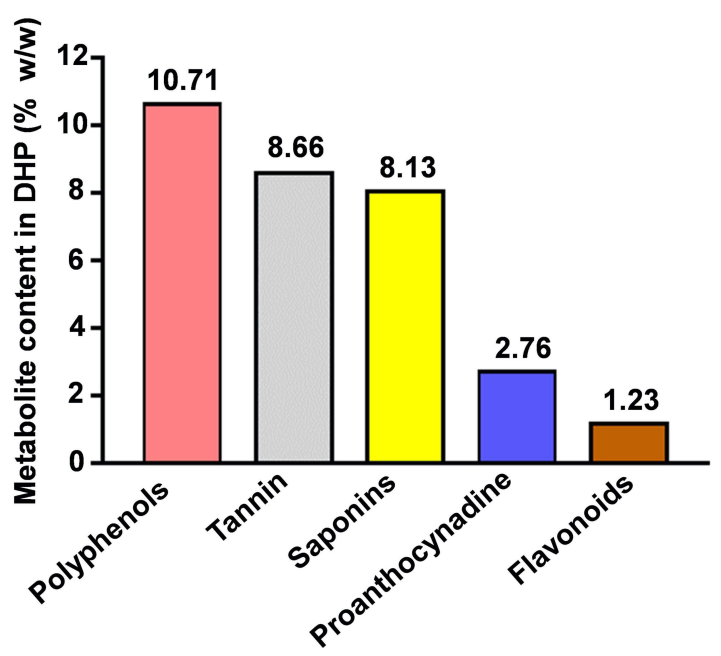

Figure 2 Compositional and physico-chemical analysis unveils DHP as a rich source of secondary metabolites. (A) Heat map visualization of the percent contribution of each plant family in DHP. Legend towards right indicating the colour intensity and corresponding percentage (\%) contribution. (B) Pie graph depicting the percent (\%) contribution of plant parts used in formulating DHP. (C) Bar graph showing the content $(\% \mathrm{w} / \mathrm{w})$ of secondary metabolites identified in DHP.

Abbreviations: DHP, Divya-Herbal-Peya.

higher at $37^{\circ} \mathrm{C}$ as compared to control, suggesting an occurrence of behavioural fever in zebrafish (experimental set up depicted in Figure 5A). On the other hand, zebrafish in the normal control and DEX treated groups showed a preference for water at optimal temperature of $29^{\circ} \mathrm{C}$. Interestingly, groups of zebrafish which were pre-administered with DHP showed substantial curtailment in thermal preferences in a dose-dependent manner (Figure 5B). The number of fish spending time at higher temperature was maximum for LPS-treated group whereas this number was drastically less for control and DHP-142 $\mu \mathrm{g} / \mathrm{kg}$ treated groups. This indicates that, DHP preadministration rescues zebrafish from LPS-induced behavioural fever (Figure 5C). Elevated C-reactive protein (CRP) in tissues is considered as a crucial hallmark of enhanced immunological response towards microbial infection. ${ }^{20}$ In line with this, we determined that a 10-fold rise in tissue CRP levels in LPS-treated zebrafish, whereas the zebrafish maintained on feed incorporating DHP-142 $\mu \mathrm{g} / \mathrm{kg}$ showed CRP levels comparable to control group (Figure 5D). DHP feed indeed regulate the CRP levels in LPS challenged zebrafish in a dose dependent manner.

\section{DHP Rescues LPS-Induced Caudal Fin Damage in Zebrafish Model of Inflammation}

Caudal fin damage is an important parameter of evaluating the severity of inflammation and reflects the acute inflammatory response. ${ }^{21}$ Phenotypic screening conducted on caudal fin showed that LPS treatment damaged the caudal fin and resulted in mild discolouration. DEX and DHP pre-treatment, however, maintained the caudal fin anatomy as compared to the normal control group (Figure 6). Together, we propose DHP as an effective herbal immunomodulator to obliterate the LPS mediated pathophysiology.

\section{DHP Pre-Administration Alleviates the Upregulated Levels of Proinflammatory Genes}

LPS challenge has been known to stimulate the immune response and releases inflammatory cytokines. ${ }^{22}$ To determine the same in LPS-treated zebrafish we assessed the expression levels of hallmark genes that are upregulated during inflammatory response. TNF $\alpha$, IL-6, IL- $1 \beta$ expression levels were 6-, 14- and 3- folds higher, respectively, in LPS-treated zebrafish as compared to saline treated zebrafish (NC). Interestingly, the relative mRNA expression levels of TNF $\alpha$, IL-6, IL- $1 \beta$ in zebrafish feeding upon DHP-142 $\mu \mathrm{g} / \mathrm{kg}$ were approximate with those of the control group (Figure 7). Here, we conclude that DHP is a 
Table 3 Weight Percentage of Herbal Components Used to Formulate DHP

\begin{tabular}{|c|c|c|c|c|c|}
\hline $\begin{array}{l}\text { S. } \\
\text { No. }\end{array}$ & Binomial Name & $\begin{array}{l}\text { Plant Part Used for Preparing } \\
\text { Formulation }\end{array}$ & $\begin{array}{l}w / w \\
(\%)\end{array}$ & Family & $\begin{array}{l}\text { Common Name in } \\
\text { English }\end{array}$ \\
\hline 1 & Amomum subulatum & Fruit & 7.41 & Zingiberaceae & Black Cardamom \\
\hline 2 & $\begin{array}{l}\text { Cinnamomum } \\
\text { zeylanicum }\end{array}$ & Bark & II.II & Lauraceae & Cinnamon \\
\hline 3 & Cymbopogon citratus & Whole plant & II.II & Poaceae & West Indian Lemon Grass \\
\hline 4 & Elettaria cardamomum & Fruit & 3.7 & Zingiberaceae & Green Cardamom \\
\hline 5 & Glycyrrhiza glabra & Root & $|4.8|$ & Leguminosae & Liquorice \\
\hline 6 & Myristica fragrans & Aril & 1.85 & Myristicaceae & Nutmeg \\
\hline 7 & Ocimum basilicum & Whole plant & 3.7 & Lamiaceae & Basil \\
\hline 8 & Ocimum sanctum & Whole plant & 7.41 & Lamiaceae & Holy Basil \\
\hline 9 & Piper longum & Fruit & 1.85 & Piperaceae & Long Pepper \\
\hline 10 & Piper nigrum & Fruit & 3.7 & Piperaceae & Black Pepper \\
\hline 11 & Pterocarpus santalinus & Heart Wood & 7.41 & Leguminosae & Red Sandalwood \\
\hline 12 & Rosa centifolia & Flower petal & 7.42 & Rosaceae & Indian Cabbage Rose \\
\hline 13 & Terminalia arjuna & Bark & 7.41 & Combretaceae & Arjuna \\
\hline 14 & Zingiber officinale & Root & II.II & Zingiberaceae & Ginger \\
\hline
\end{tabular}

potent immunomodulator that can subside the heightened inflammatory response.

\section{Discussion}

Our body is vulnerable to a plethora of infections; it is the differential immune response of an individual that determines the extent, severity, and associated clinical manifestations of that infection. Activation of an inflammatory immune response is a natural host defence mechanism against pathogens. However, in cases of recurrent infections, chronic activation of inflammatory response can cause severe tissue damage. Therefore, it is important to acquire effective immunity that enables a fast containment of pathogens with a short period inflammatory response. Several nutrients, vitamins and food supplements are available over the counter for enhancing immunity but the majority of them are either synthetic or lack scientific evidence.

Practitioners of Ayurveda recommend the use of DHP to combat the inflammatory symptoms that appear during mild recurrent infections, fever, cold and cough. Our study experimentally investigated the rationale behind the utilization of DHP. Thorough compositional analysis of DHP demonstrated the presence of herbs that have proven anti-inflammatory properties (Figure 2). We identified some signature phytometabolites in DHP through HPTLC and UHPLC that exhibit proven therapeutic potential (Figure 3A-D); most dominant being gallic acid. In vitro and in vivo studies have demonstrated the anti-inflammatory and anti-microbial properties of gallic acid. ${ }^{23,24}$ Ellagic acid another substantially identified phytometabolite belonging to the tannin class of polyphenols also exhibits scientifically proven anti-oxidant, anti-microbial and anti-inflammatory activities. ${ }^{25-27}$

Roots of Glycyrrhiza glabra in DHP served as a rich source of glycyrrhizin which was also identified through both, HPTLC and UHPLC techniques. Various in vitro and in vivo models determined that glycyrrhizin cures asthma by inhibiting the heightened inflammatory response via PI3K/Akt/GSK3 $\beta$ pathway. ${ }^{28,29}$ Another study showed that glycyrrhizin also retards the transactivation of NF $\kappa \mathrm{B}$ like dexamethasone. ${ }^{30}$ Rosmarinic acid is an important polyphenol sourced from Lamiaceae family members which account for $11 \%$ of the total composition in DHP. Rosmarinic acid is consumed as a food supplement because of numerous health benefits and scientific indices referring to anti-inflammatory and anti-oxidant properties. $^{31-33}$ Protocatechuic acid and 6-gingerol were also determined to be active parts of DHP formulation. Scientific reports have shown that both phytometabolites have free radical scavenging activity and immunomodulatory attributes. ${ }^{34-38}$

The potent anti-microbial activity of cinnamic acid has been exploited in developing novel drugs with modified potency, solubility and bioavailability against a myriad of bacterial infections. ${ }^{39-41}$ Piper longum and Piper nigrum in DHP sourced piperine, an alkaloid class of metabolites 
A

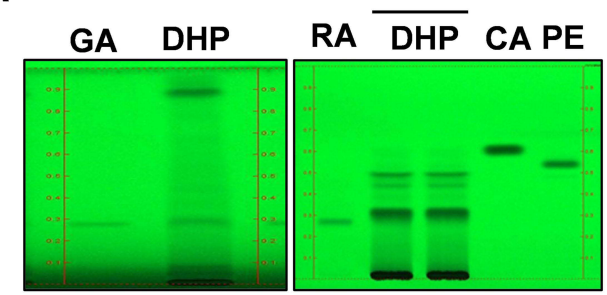

C

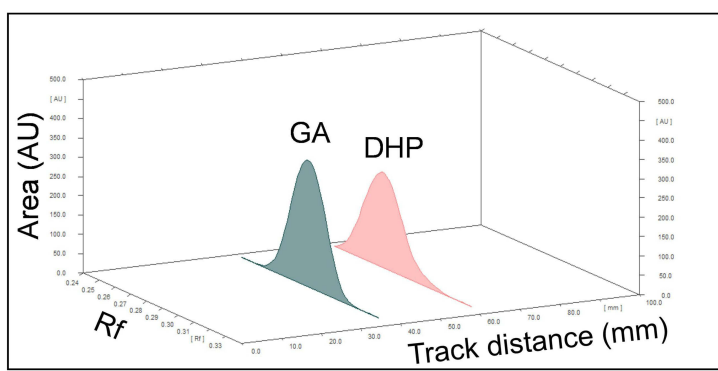

$\mathbf{E}$

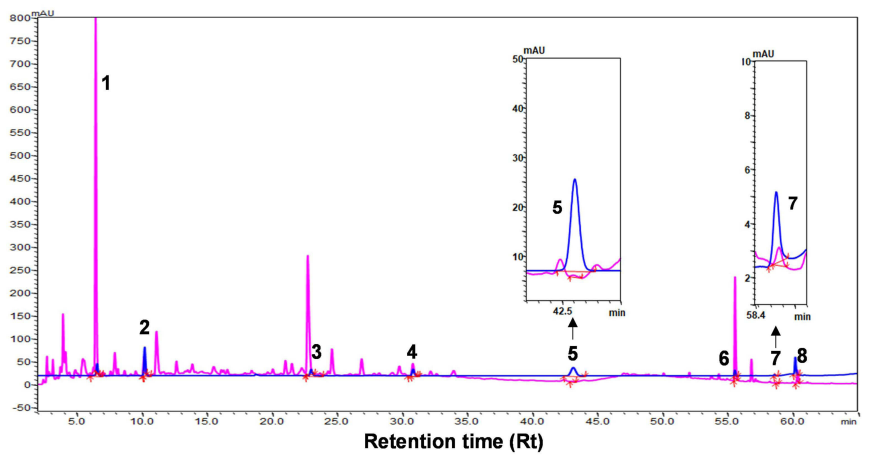

G

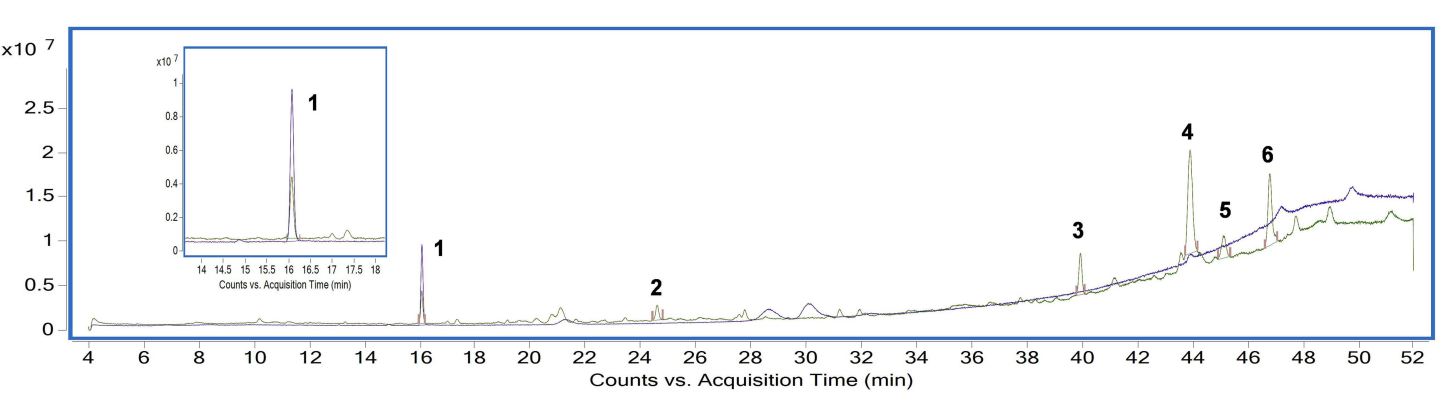

Figure 3 HPTLC, UHPLC and GC-MS based identification and quantification of the phytochemicals present in DHP. (A) (Left) The digital fingerprinting of the TLC plate captured at $254 \mathrm{~nm}$ shows the band identified in the DHP sample corresponding to GA, glycyrrhizin. (Right) Digital fingerprinting of the TLC plate captured at $254 \mathrm{~nm}$ shows the bands identified in the DHP sample corresponds to RA, CA and PE, where RA is rosmarinic acid, CA is cinnamic acid and PE is piperine. (B) Graph representing the content (in $\mu \mathrm{g} / \mathrm{mg}$ ) of indicated phytometabolites identified through HPTLC. (C) 3-D overlay densitogram recorded at 280 nm shows the appearance of peaks for RA, CA and PE in DHP sample upon reference with standards. (D) 3-D overlay densitogram monitored at $280 \mathrm{~nm}$ shows the peak for GA ie, glycyrrhizin in DHP sample and standard. (E) Chromatogram generated at $250 \mathrm{~nm}$ shows the overlay of DHP sample (pink) with the standards (blue). The numbers in the chromatogram indicate the peak numbers which were identified with reference to the retention time of standards. Peak no. 5 and 7 are zoomed in to provide a clear illustration of overlapping peaks in DHP sample and standards. (F) Bar graph demonstrating the quantification (in $\mu \mathrm{g} / \mathrm{mg}$ ) of phytochemicals identified through UHPLC. (G) GC-MS chromatogram shows the overlay of DHP sample (green) with the cinnamaldehyde standards (blue). The identification and quantification of the indicated peak numbers is briefed in Table 5. Peak number I, zoomed in the chromatogram refers to cinnamaldehyde.

Abbreviations: DHP, Divya-Herbal-Peya; HPTLC, high-Performance thin liquid chromatography; UHPLC, ultra-high-performance liquid chromatography; GC-MS, gas chromatography-mass spectrometry; RA, rosmarinic acid; CA, cinnamic acid; PE, piperine; GA, glycyrrhizin. 


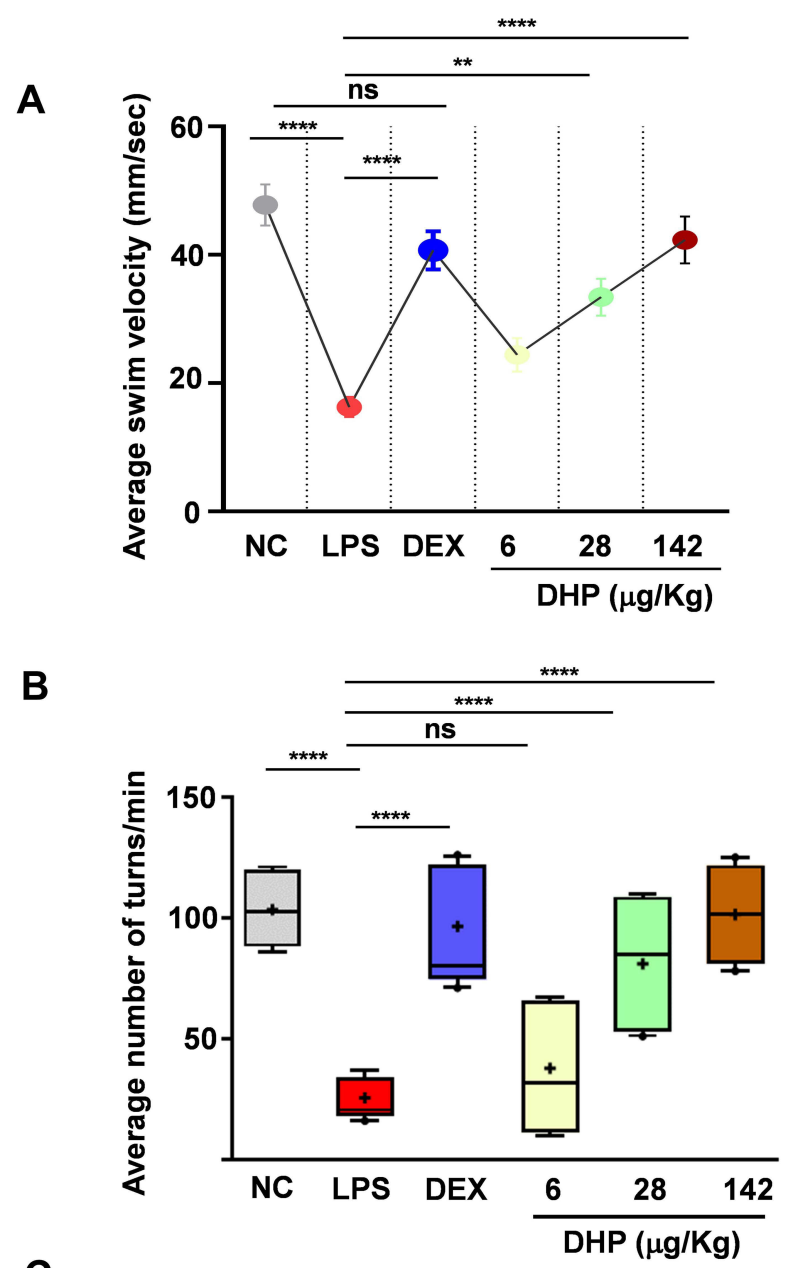

C

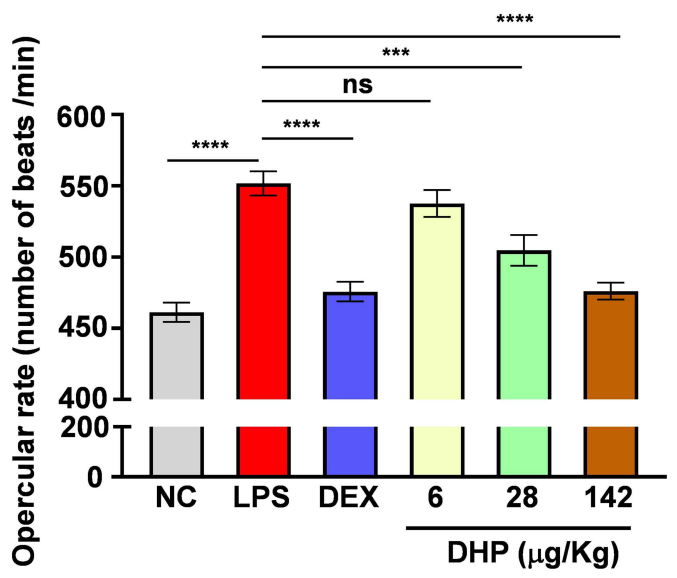

Figure 4 Pre-administration of DHP normalized LPS-stimulated aberrant behavioural activities in zebrafish model. (A) Graph showing average velocity of each group ( $=24$ in each group). The circles in graph represents the values mean \pm SEM velocity of each group. (B) The box and whisker plot depicting the average number of turns (turns/ $\mathrm{min}$ ) taken by each zebrafish was calculated ( $\mathrm{n}=24$ in each group). The mean of each group is represented by + sign. (C) Number of opercular beats were recorded for 3 min in each zebrafish. On that basis we calculated opercular beat frequency per min. Bar chart showing the average opercular frequency of each group ( $n=24$ in each group). Error bars in represent \pm SEM; significance of data represented as, $* * p<0.005, * * * p<0.0005, * * * *<<0.00005$ and not significant (ns) if $p>0.05$.

Abbreviations: DHP, Divya- Herbal-Peya; DEX, dexamethasone; LPS, lipopolysaccharide; NC, normal control.

identified through UHPLC. Piperine harbour anti-inflammatory, anti-microbial, analgesic, antipyretic, antioxidant properties and can also enhance the bioavailability of some drugs. ${ }^{42}$ We identified and quantified cinnamaldehyde through GC-MS which also exhibits proven anti-microbial and anti-inflammatory activities. ${ }^{43}$ 
Table 4 Identification and Quantification of Phytochemicals Present in DHP by UHPLC

\begin{tabular}{|c|c|c|c|c|c|c|}
\hline $\begin{array}{l}\text { Peak No. } \\
*\end{array}$ & $t_{\mathbf{R}}{ }^{\#}$ & $\begin{array}{l}\text { Phyto-Chemical } \\
\text { Identified }\end{array}$ & $\begin{array}{l}\text { Molecular } \\
\text { Formula }\end{array}$ & $\begin{array}{l}\text { Molecular } \\
\text { Weight }\end{array}$ & Chemical Structure** & $\begin{array}{l}\text { Content }(\mu \mathrm{g} / \\
\mathrm{mg})\end{array}$ \\
\hline I & 6.47 & Gallic acid & $\mathrm{C}_{7} \mathrm{H}_{6} \mathrm{O}_{5}$ & 170.12 & & 24.46 \\
\hline 2 & 10.14 & Protocatechuic acid & $\mathrm{C}_{7} \mathrm{H}_{6} \mathrm{O}_{4}$ & 154.12 & & 0.24 \\
\hline 3 & 22.77 & Ellagic acid & $\mathrm{C}_{14} \mathrm{H}_{6} \mathrm{O}_{8}$ & 302.19 & & 4.02 \\
\hline 4 & 30.75 & Rosmarinic acid & $\mathrm{C}_{18} \mathrm{H}_{16} \mathrm{O}_{8}$ & 360.3 & & 0.65 \\
\hline 5 & 43.05 & Cinnamic acid & $\mathrm{C}_{9} \mathrm{H}_{8} \mathrm{O}_{2}$ & 148.16 & & 0.11 \\
\hline 6 & 55.57 & Glycyrrhizin & $\mathrm{C}_{42} \mathrm{H}_{62} \mathrm{O}_{16}$ & 822.9 & & 2.93 \\
\hline 7 & 58.49 & 6-Gingerol & $\mathrm{C}_{17} \mathrm{H}_{26} \mathrm{O}_{4}$ & 294.4 & & 0.39 \\
\hline 8 & 60.09 & Piperine & $\mathrm{C}_{17} \mathrm{H}_{19} \mathrm{NO}_{3}$ & 285.34 & & 0.03 \\
\hline
\end{tabular}

Notes: *As indicated in UHPLC chromatogram (Figure 3E) **Adapted from PubChem ${ }^{*}$ Retention time (in min). 
Table 5 Identification and Quantification of Volatile Compounds Present in DHP by GC-MS

\begin{tabular}{|c|c|c|c|c|c|c|}
\hline $\begin{array}{l}\text { Peak } \\
\text { No.* }\end{array}$ & $\mathbf{t}_{\mathbf{R}} \#$ & Compound Identified & $\begin{array}{l}\text { Molecular } \\
\text { Formula }\end{array}$ & $\begin{array}{l}\text { Area } \\
(\%)\end{array}$ & Chemical Structure ** & $\begin{array}{l}\text { Content }(\mu \mathrm{g} / \\
\mathrm{mg})\end{array}$ \\
\hline 1 & 16.07 & Cinnamaldehyde & $\mathrm{C}_{9} \mathrm{H}_{8} \mathrm{O}$ & 6.49 & & 2.52 \\
\hline 2 & 24.60 & Widdrol & $\mathrm{C}_{15} \mathrm{H}_{26} \mathrm{O}$ & 4.19 & & 2.73 \\
\hline 3 & 39.94 & Gingerol & $\mathrm{C}_{17} \mathrm{H}_{26} \mathrm{O}_{4}$ & 11.33 & & 9.80 \\
\hline 4 & 43.90 & n-Hexadecanoic acid & $\mathrm{C}_{16} \mathrm{H}_{32} \mathrm{O}_{2}$ & 43.04 & & 32.39 \\
\hline 5 & 45.11 & $\begin{array}{l}\text { Octaethylene glycol monododecyl } \\
\text { ether }\end{array}$ & $\mathrm{C}_{28} \mathrm{H}_{58} \mathrm{O}_{9}$ & 8.93 & & 14.14 \\
\hline 6 & 46.80 & Octaethylene glycol & $\mathrm{C}_{16} \mathrm{H}_{34} \mathrm{O}_{9}$ & 26.01 & & 28.28 \\
\hline
\end{tabular}

Notes: *As indicated in GC-MS chromatogram (Figure 3G) ${ }^{* *}$ Adapted from PubChem ${ }^{\#}$ Retention time (in min).

Taken together, a majority of the phytometabolites identified in DHP extract are substantially supported by in vitro and in vivo research studies for their anti-inflammatory and anti-microbial properties. Therefore, we hypothesized that DHP exhibits immunomodulatory properties and probably is capable of remodulating the immune response. This perhaps could be the reason for recommending DHP to mitigate the infection related symptomatology. LPS induction is known to activate inflammatory and stress responses that can also result into aberrant behaviours. Adult zebrafish display a myriad of mature behaviours related to anxiety, locomotion, learning, social interactions, and temperature preferences, which encouraged us to consider them apt for this study. Hence, we outlined out study in LPS-induced zebrafish, that is already an established model of inflammation. During our preliminary experiments conducted for model optimization, we also observed behavioural sickness and anomalous locomotory patterns upon LPS challenge that encouraged us to consider zebrafish as an experimental model over higher vertebrate. Our study aimed to determine the preventive action of DHP on LPS-induced abnormal behavioural response in zebrafish. Through abnormal behavioural response we mean manifestations observed in quantifiable actions as a result of biochemical and physiological changes that have occurred post LPS-induction. Our results indicate significantly reduced average swim velocity and turning rate upon LPS-induction in zebrafish. However, the swim kinetics and turning rate was observed to be normal in groups which were either pre-treated with 
B
A

Interconnected thermal gradient tanks
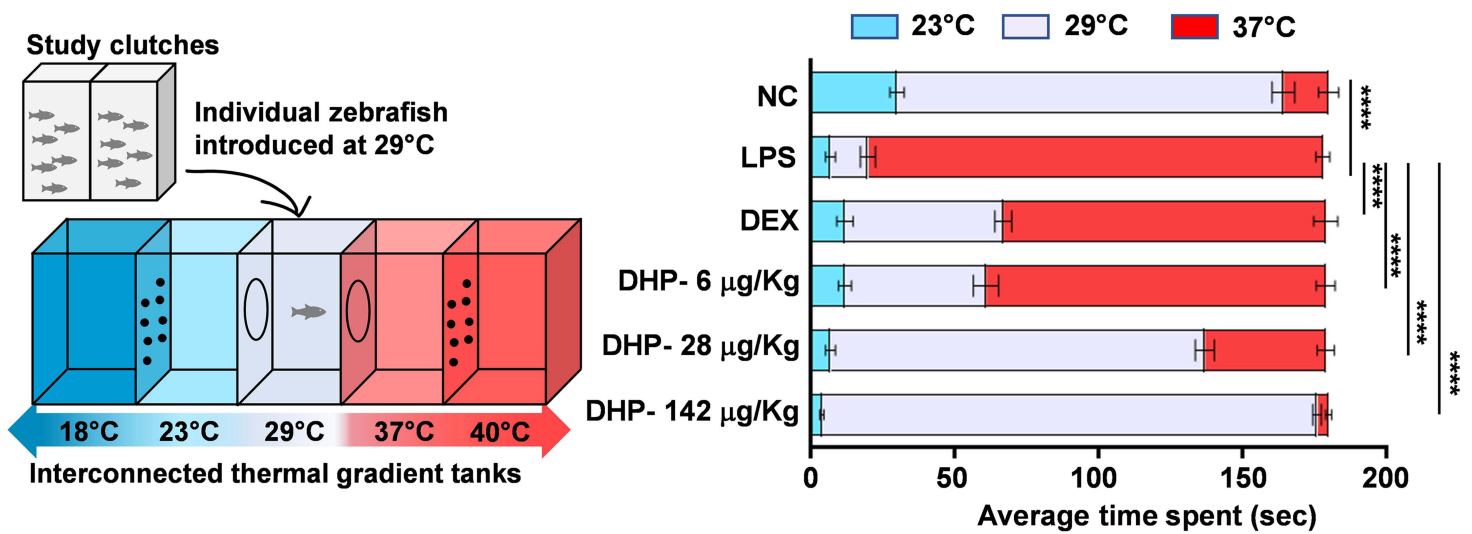

C

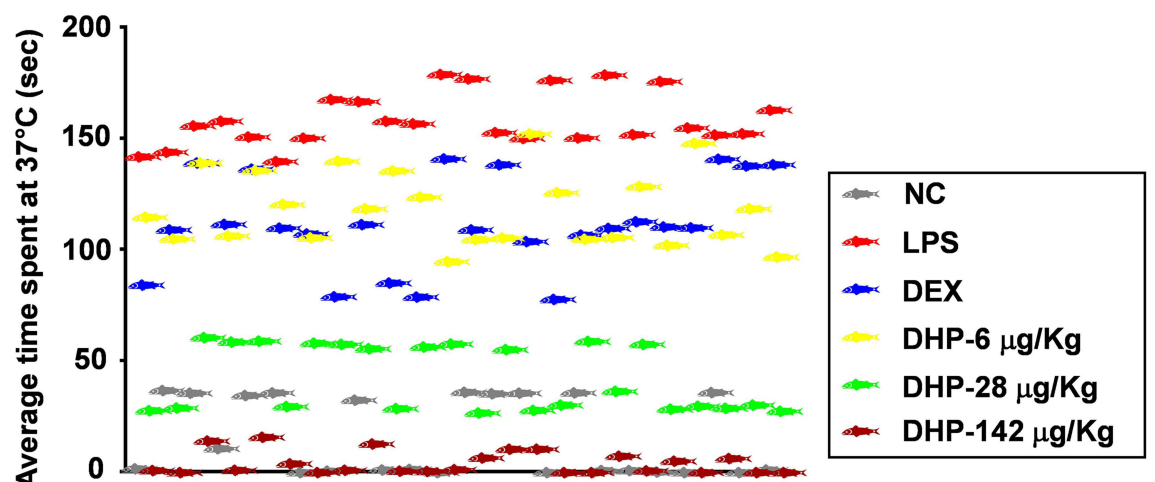

Each fish symbol represents a zebrafish subject

D

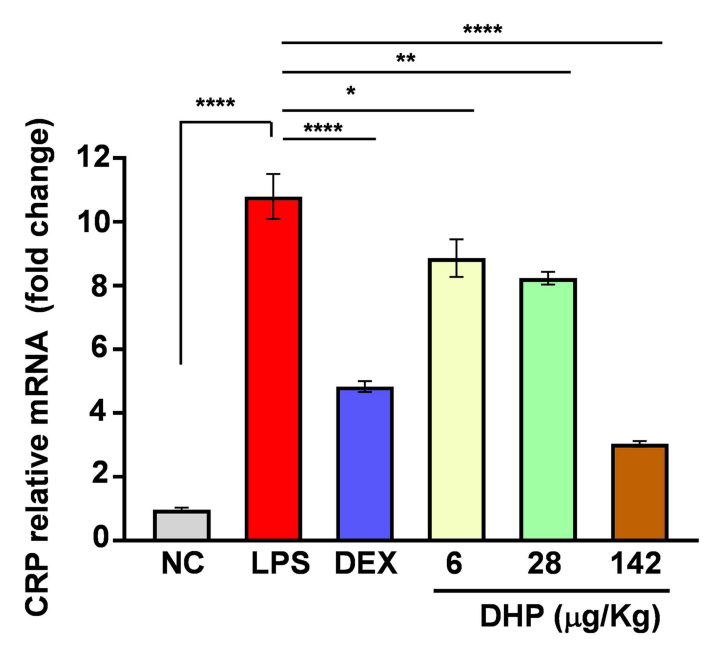

Figure 5 Zebrafish model pre-treated with DHP were impervious to LPS-stimulated behavioural fever. (A) Diagrammatic representation of experimental set up to study behavioural fever in zebrafish. Adjacent perforated tanks at $18^{\circ} \mathrm{C}$ (low) and $40{ }^{\circ} \mathrm{C}$ (high) regulated the indicated temperatures of interconnected thermal tanks. Temperature preferences for zebrafish were studied by introducing zebrafish individually in the thermal tank at $29^{\circ} \mathrm{C}$. (B) Horizontal bar graph depicting the average time spent (s) by six groups independently at $23{ }^{\circ} \mathrm{C}, 29^{\circ} \mathrm{C}$ and $37^{\circ} \mathrm{C}\left(\mathrm{n}=24\right.$ in each group). The significance is shown only for the difference in average time spent among six groups at $37{ }^{\circ} \mathrm{C}$. (C) The scatter plot represents time spend by each zebrafish at $37{ }^{\circ} \mathrm{C}(\mathrm{n}=24)$. Each fish symbol represents a zebrafish subject that participated in experimental set up described in (A). The colour of fish symbol represents their respective group. (D). Fold change in mRNA expression levels of CRP ( $n=3$ in each group). Error bars in (B and D) represent $\pm S E M$; significance of data represented as, ${ }^{*} p<0.05$, ${ }^{* *} p<0.005$, ${ }^{*} * * * p<0.00005$.

Abbreviations: DHP, Divya-Herbal-Peya; DEX, dexamethasone; LPS, lipopolysaccharide; NC, normal control; CRP, C-reactive protein. 

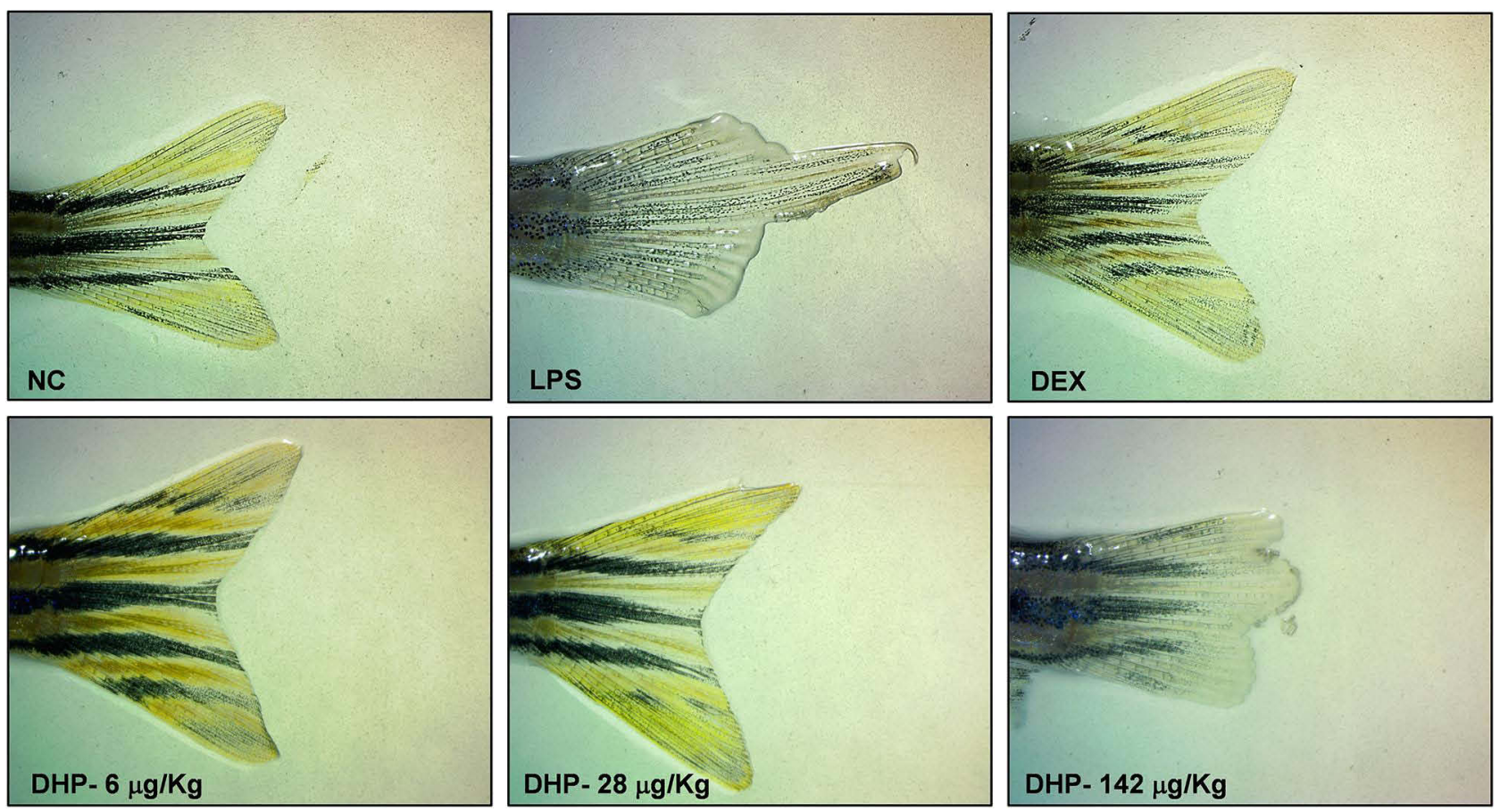

Figure 6 DHP rescues LPS-induced caudal fin damage in zebrafish. Representative images of the caudal fin damage from each group (Group I -NC; Group II- LPS; Group III-

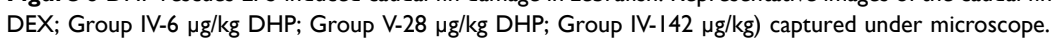

Abbreviations: DHP, Divya-Herbal-Peya; DEX, dexamethasone; LPS, lipopolysaccharide; NC, normal control.

DEX or DHP (Figure 4A-D). Similarly, opercular beat rate, which is an established parameter of assessing stress was significantly higher in LPS treated zebrafish. Elevated opercular frequency also suggest enhanced respiratory rate and oxygen demand. Moreover, a previous report has also shown a direct proportionality of opercular rate with heart beat. ${ }^{44}$ These studies hence, indicate that erratic opercular rate signifies the abnormalities in respiratory and cardiovascular functioning of fish.

DHP incorporated feeds showed the negligible impact of LPS on opercular frequency rate corroborated our claim of DHP being immunomodulatory and also capable of maintaining a normal pathophysiology during infection (Figure 4E and F). Along similar lines, DHP pre-treated zebrafish showed negligible behavioural fever even after LPS-stimulation (Figure 5A-D). Endotherms respond to infection with physiological fever, ectotherms on the other hand respond behaviourally by moving in water at a higher temperature. ${ }^{45}$ These thermal preferences are referred as behavioural fever. Fish thermoregulate their body temperature by relocating themselves to a higher temperature to enhance the immune response. DHP or DEX pre-treated zebrafish preferred to stay in water maintained at the optimal temperature $\left(29^{\circ} \mathrm{C}\right)$, indicating DHP treatment negated the LPS-mediated immune response. Due to LPS mediated production of cytokines, inflammatory tissue injuries are commonly observed. We also observed caudal fin damage in LPS treated zebrafish, although with zero mortality. However, DHP pre-treatment did not show substantial caudal fin damage suggesting that DHP probably regulated the LPS induced inflammatory response. LPS act as a potent inducer of immune system that triggers TNF $\alpha$, IL- 6 and IL- $1 \beta$ that are also known to be secreted during common infections like cold, cough and fever. We determined that LPS stimulated the inflammatory response in zebrafish by elevating gene expression levels of TNF $\alpha$, IL-6 and IL-1 $\beta$. Prophylactic treatment of DHP on the other hand mediated dose dependent reduction in TNF $\alpha$, IL6 and IL-1 $\beta$ gene expression levels suggesting that DHP exhibits potential immunomodulatory properties (Figures 6 and 7). This might be an important mechanism of action through which DHP treated zebrafish become null for aberrant behavioural response even after LPS treatment.

DHP might have nutraceutical implications, wherein the herbal decoction can be consumed by healthy 

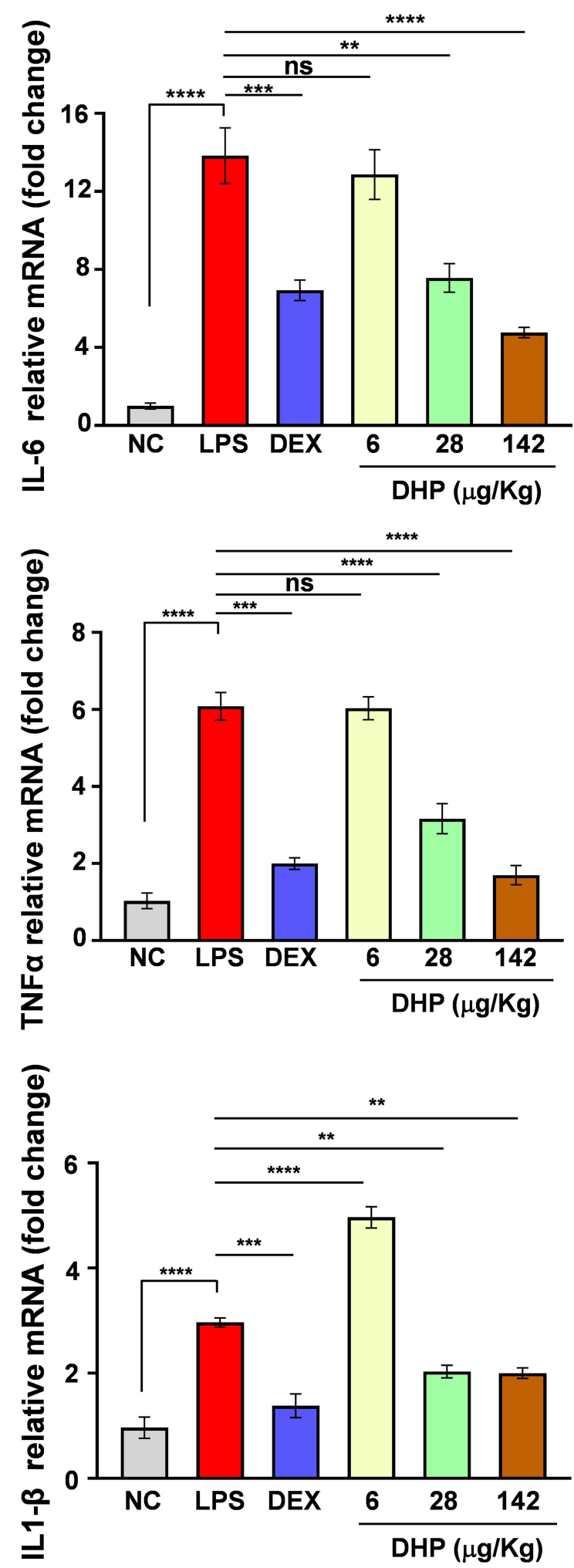

Figure 7 DHP feed harmonizes the LPS-stimulated cytokine rush in zebrafish. Fold change in relative mRNA expression levels of IL-6, TNF $\alpha$, IL-I $\beta$ ( $n=3$ in each group). Error bars represent \pm SEM; significance of data represented as, ${ }^{* *} p<0.005,{ }^{* * *} p<0.0005,{ }^{* * * *} p<0.00005$ and not significant (ns) if $p>0.05$.

Abbreviations: DHP, Divya-Herbal-Peya; DEX, dexamethasone; LPS, lipopolysaccharide; NC, normal control; IL-6, interleukin-6; TNF $\alpha$, tumor necrosis factor alpha; IL-I $\beta$, interleukinIbeta.

individuals for preventing recurrent infections. in vitro and in vivo experimental models. The therapeutic Collectively, these results have encouraged us to further potential of DHP as a herbal drink, however, has not been decipher the mechanistic mode of action of DHP through investigated in our study. 


\section{Conclusion}

DHP prevented the LPS-induced inflammatory response. It was prophylactically administered to healthy subjects that probably imparted nutraceutical health benefit to zebrafish model against LPS. Our study demonstrates that DHP has a scientific basis for being prescribed to relieve symptoms associated with mild infections.

\section{Abbreviations}

DHP, Divya-Herbal-Peya; HPTLC, high-performance thin liquid chromatography; UHPLC, ultra-high-performance liquid chromatography; GC-MS, gas chromatographymass spectrometry; LPS, lipopolysaccharides; TNF, tumor necrosis factor; IL-6, interleukin 6; IL-1 $\beta$, interleukin 1 beta.

\section{Acknowledgments}

We appreciate the zebrafish test facilities and experimentations at our CRO partner, Pentagrit Labs, Chennai, India. We thank Ms. Meenu Tomer, Mr. Yash Varshney and Mr. Sudeep Verma for phytochemical analysis. We acknowledge Mr. Shoor Singh, Mr. Arun Raturi and Dr. Preeti Raj for the excellent support in generating video graphics. We extend our gratitude to Ms. Priyanka Kandpal, Mr. Tarun Rajput, Mr. Gagan Kumar and Mr. Lalit Mohan for their swift administrative supports. The test article (DHP) was sourced from Divya Pharmacy, Haridwar, Uttarakhand, India. Besides, providing the test article, Divya Pharmacy was not involved in any aspect of this study. Divya Pharmacy, Haridwar India, manufactures and sells many herbal medicinal products, including DHP.

\section{Author Contributions}

All authors substantially contributed to conception of design, acquisition of data, analysis and interpretation of data. Assisted/cooperated/took part in drafting the work or revising it critically for important intellectual content; have consent in final approval of the version to be published. All authors agree to be accountable for all aspects of the work in ensuring that questions related to the accuracy or integrity of any part of the work are appropriately investigated and resolve.

\section{Funding}

This presented work has been conducted using internal research funds from a non-commercial and non-profit Patanjali Research Foundation Trust, Haridwar, India.

\section{Disclosure}

Acharya Balkrishna is an honorary trustee in Divya Yog Mandir Trust that governs Divya Pharmacy, Haridwar. In addition, Acharya Balkrishna holds an honorary managerial position in Patanjali Ayurved Ltd., Haridwar, Uttarakhand, India. Savita Lochab, Monali Joshi, Jyotish Srivastava, and Anurag Varshney are employed at Patanjali Research Institute which is governed by Patanjali Research Foundation Trust (PRFT), Haridwar, Uttarakhand, India, a not-for-profit organization. In addition, Anurag Varshney is an adjunct professor in Department of Allied and Applied Sciences, University of Patanjali, NH-58, Haridwar-249405, Uttarakhand, India; and in the Special Centre for Systems Medicine, Jawaharlal Nehru University, New Delhi-110067, India. The authors report no other conflicts of interest in this work.

\section{References}

1. Gokani T. Ayurveda-the science of healing. Headache. 2014;54 (6):1103-1106. doi:10.1111/head.12363

2. Khanal P, Duyu T, Patil BM, et al. Network pharmacology of AYUSH recommended immune-boosting medicinal plants against COVID-19. J Ayurveda Integr Med. 2020. doi:10.1016/j.jaim.2020.11.004

3. Parasuraman S, Thing GS, Dhanaraj SA. Polyherbal formulation: concept of ayurveda. Pharmacogn Rev. 2014;8(16):73-80. doi:10.4103/0973-7847.134229

4. Novoa B, Figueras A. Zebrafish: model for the study of inflammation and the innate immune response to infectious diseases. Adv Exp Med Biol. 2012;946:253-275. doi:10.1007/978-1-4614-0106-3_15

5. Cassar S, Adatto I, Freeman JL, et al. Use of zebrafish in drug discovery toxicology. Chem Res Toxicol. 2020;33:95-118. doi:10.1021/acs.chemrestox.9b00335

6. Álvarez-rodríguez M, Pereiro P, Reyes-López FE, Tort L, Figueras A, Novoa B. Analysis of the long-lived responses induced by immunostimulants and their effects on a viral infection in Zebrafish (Danio rerio). Front Immunol. 2018;9. doi:10.3389/fimmu.2018.01575

7. Mehrdana F, Kania PW, Nazemi S, Buchmann K. Immunomodulatory effects of excretory/ secretory compounds from Contracaecum osculatum larvae in a zebrafish inflammation model. PLoS One. 2017;12: e0181277. doi:10.1371/journal.pone.0181277

8. Singleton VL, Rossi JA. Colorimetry of total phenolics with phosphomolybdic-phosphotungstic acid reagents. Am J Enol Vitic. 1965;16(3):144-158.

9. Malik M, Sharif A, Hassan SU, et al. Amelioration of hyperglycaemia and modulation of pro-inflammatory cytokines by Tamarix gallica fractions in alloxan induced diabetic rats. Arch Physiol Biochem. 2020:1-10. doi:10.1080/13813455.2020.1788099

10. Meharie BG, Tunta TA. Evaluation of diuretic activity and phytochemical contents of aqueous extract of the shoot apex of podocarpus falcactus. J Exp Pharmacol. 2020;12:629-641. doi:10.2147/JEP. S287277

11. Aryal S, Baniya MK, Danekhu K, Kunwar P, Gurung R, Koirala N. Total phenolic content, flavonoid content and antioxidant potential of wild vegetables from Western Nepal. Plants. 2019;8(4). doi:10.3390/ plants 8040096

12. Wallace CK, Bright LA, Marx JO, Andersen RP, Mullins MC, Carty AJ. Effectiveness of rapid cooling as a method of euthanasia for young Zebrafish (Danio rerio). $J$ Am Assoc Lab Anim Sci. 2018;57:58-63. 
13. Balkrishna A, Solleti SK, Verma S, Varshney A. Validation of a novel zebrafish model of dengue virus (DENV-3) pathology using the pentaherbal medicine denguenil vati. Biomolecules. 2020;10(7):971. doi:10.3390/biom 10070971

14. Schneider CA, Rasband WS, Eliceiri KW. NIH Image to ImageJ: 25 years of image analysis. Nat Methods. 2012;9(7):671-675. doi:10.1038/nmeth.2089

15. Balkrishna A, Solleti SK, Verma S, Varshney A. Application of humanized zebrafish model in the suppression of SARS-CoV-2 spike protein induced pathology by tri-herbal medicine coronil via cytokine modulation. Molecules. 2020;25:21. doi:10.3390/molecules25215091

16. Ye J, Coulouris G, Zaretskaya I, Cutcutache I, Rozen S, Madden TL. Primer-BLAST: a tool to design target-specific primers for polymerase chain reaction. BMC Bioinform. 2012;13:134. doi:10.1186/1471-210513-134

17. Mushtaq A, Akbar S, Zargar MA, et al. Phytochemical screening, physicochemical properties, acute toxicity testing and screening of hypoglycaemic activity of extracts of eremurus himalaicus baker in normoglycaemic Wistar strain albino rats. Biomed Res Int. 2014;2014:1-6. doi:10.1155/2014/867547

18. Yang LL, Wang GQ, Yang LM, Huang ZB, Zhang WQ, Yu LZ. Endotoxin molecule lipopolysaccharide-induced zebrafish inflammation model: a novel screening method for anti-inflammatory drugs. Molecules. 2014;19(2):2390-2409. doi:10.3390/molecules 19022390

19. Boltana S, Rey S, Roher N, et al. Behavioural fever is a synergic signal amplifying the innate immune response. Proc Biol Sci. 2013;280(1766):20131381. doi:10.1098/rspb.2013.1381

20. Bello-Perez M, Pereiro P, Coll J, Novoa B, Perez L, Falco A. Zebrafish C-reactive protein isoforms inhibit SVCV replication by blocking autophagy through interactions with cell membrane cholesterol. Sci Rep. 2020;10(1):566. doi:10.1038/s41598-020-57501-0

21. Miskolci V, Squirrell J, Rindy J, et al. Distinct inflammatory and wound healing responses to complex caudal fin injuries of larval zebrafish. Elife. 2019;8. doi:10.7554/eLife.45976

22. Nakagawa R, Naka T, Tsutsui $H$, et al. SOCS-1 participates in negative regulation of LPS responses. Immunity. 2002;17(5):677687. doi:10.1016/s1074-7613(02)00449-1

23. Al Zahrani NA, El-Shishtawy RM, Asiri AM. Recent developments of gallic acid derivatives and their hybrids in medicinal chemistry: a review. Eur J Med Chem. 2020;204:112609. doi:10.1016/j.ejmech.2020.112609

24. Nouri A, Heibati F, Heidarian E. Gallic acid exerts anti-inflammatory, anti-oxidative stress, and nephroprotective effects against paraquatinduced renal injury in male rats. Naunyn Schmiedebergs Arch Pharmacol. 2021;394(1):1-9. doi:10.1007/s00210-020-01931-0

25. Julio de Souza AL, Beatriz Mahler Pereira A, Robison de Oliveira J, et al. Dermatophagoides pteronyssinus-induced pro-inflammatory responses mediated via STAT3 and NF-kappaB signaling pathways in human bronchial epithelial cells - Inhibitory effects of Lafoensia pacari and ellagic acid. J Pharmacol Sci. 2020;142(4):157-164. doi:10.1016/j.jphs.2020.01.004

26. Mottola F, Scudiero N, Iovine C, Santonastaso M, Rocco L. Protective activity of ellagic acid in counteract oxidative stress damage in zebrafish embryonic development. Ecotoxicol Env Saf. 2020;197:110642. doi:10.1016/j.ecoenv.2020.110642

27. Murphy MT, Qin X, Kaul S, et al. The polyphenol ellagic acid exerts anti-inflammatory actions via disruption of store-operated calcium entry (SOCE) pathway activators and coupling mediators. Eur J Pharmacol. 2020;875:173036. doi:10.1016/j.ejphar.2020.173036

28. Kao TC, Shyu MH, Yen GC. Glycyrrhizic acid and 18ß-glycyrrhetinic acid inhibit inflammation via PI3K/Akt/GSK3 $\beta$ signaling and glucocorticoid receptor activation. $J$ Agric Food Chem. 2010;58:8623-8629. doi:10.1021/jf101841r

29. Yu JY, Ha JY, Kim KM, Jung YS, Jung JC, Oh S. Anti-inflammatory activities of licorice extract and its active compounds, glycyrrhizic acid, liquiritin and liquiritigenin, in BV2 cells and mice liver. Molecules. 2015;20:13041-13054. doi:10.3390/molecules200713041
30. Takei H, Baba Y, Hisatsune A, et al. Glycyrrhizin inhibits interleukin8 production and nuclear factor- $\mathrm{\kappa B}$ activity in lung epithelial cells, but not through glucocorticoid receptors. $J$ Pharmacol Sci. 2008;106:460-468. doi:10.1254/jphs.FP0072378

31. Wei Y, Chen J, Cai GE, et al. Rosmarinic acid regulates microglial M1/M2 polarization via the PDPK1/Akt/HIF pathway under conditions of neuroinflammation. Inflammation. 2020. doi:10.1007/ s10753-020-01314-w

32. Nyandwi JB, Ko YS, Jin H, Yun SP, Park SW, Kim HJ. Rosmarinic acid inhibits oxLDL-induced inflammasome activation under highglucose conditions through downregulating the p38-FOXO1-TXNIP pathway. Biochem Pharmacol. 2020;182:114246. doi:10.1016/j. bcp. 2020.114246

33. Luo C, Zou L, Sun H, et al. A review of the anti-inflammatory effects of rosmarinic acid on inflammatory diseases. Front Pharmacol. 2020;11:153. doi:10.3389/fphar.2020.00153

34. Bhaskar A, Kumari A, Singh M, et al. [6]-Gingerol exhibits potent anti-mycobacterial and immunomodulatory activity against tuberculosis. Int Immunopharmacol. 2020;87:106809. doi:10.1016/j. intimp.2020.106809

35. Hong MK, Hu LL, Zhang YX, et al. 6-Gingerol ameliorates sepsisinduced liver injury through the $\mathrm{Nrf2}$ pathway. Int Immunopharmacol. 2020;80:106196. doi:10.1016/j.intimp.202 0.106196

36. Liu Y, Deng S, Zhang Z, et al. 6-Gingerol attenuates microgliamediated neuroinflammation and ischemic brain injuries through Akt-mTOR-STAT3 signaling pathway. Eur $J$ Pharmacol. 2020;883:173294. doi:10.1016/j.ejphar.2020.173294

37. Kaewmool C, Kongtawelert P, Phitak T, Pothacharoen P, Udomruk S. Protocatechuic acid inhibits inflammatory responses in LPS-activated BV2 microglia via regulating SIRT1/NF-kappaB pathway contributed to the suppression of microglial activation-induced PC12 cell apoptosis. $\quad J$ Neuroimmunol. 2020;341:577164. doi:10.1016/j.jneur oim. 2020.577164

38. Akanni OO, Owumi SE, Olowofela OG, Adeyanju AA, Abiola OJ, Adaramoye OA. Protocatechuic acid ameliorates testosteroneinduced benign prostatic hyperplasia through the regulation of inflammation and oxidative stress in castrated rats. $J$ Biochem Mol Toxicol. 2020;34(8):e22502. doi:10.1002/jbt.22502

39. Karatas O, Balci Yuce H, Taskan MM, et al. Cinnamic acid decreases periodontal inflammation and alveolar bone loss in experimental periodontitis. J Periodontal Res. 2020;55(5):676-685. doi:10.1111/ jre. 12754

40. Ruwizhi N, Aderibigbe BA. Cinnamic acid derivatives and their biological efficacy. Int J Mol Sci. 2020;21(16):5712. doi:10.3390/ ijms 21165712

41. Abozaid OAR, Moawed FSM, Ahmed ESA, Ibrahim ZA. Cinnamic acid nanoparticles modulate redox signal and inflammatory response in gamma irradiated rats suffering from acute pancreatitis. Biochim Biophys Acta Mol Basis Dis. 2020;1866(11):165904. doi:10.1016/j. bbadis.2020.165904

42. Meghwal M, Goswami TK. Piper nigrum and piperine: an update. Phyther Res. 2013;27(8). doi:10.1002/ptr.4972

43. Doyle AA, Stephens JC. A review of cinnamaldehyde and its derivatives as antibacterial agents. Fitoterapia. 2019;139:104405. doi:10.1016/j.fitote.2019.104405

44. Mendez-Sanchez JF, Burggren WW. Cardiorespiratory physiological phenotypic plasticity in developing air-breathing anabantid fishes (Betta splendens and Trichopodus trichopterus). Physiol Rep. 2017;5(15). doi:10.14814/phy2.13359

45. Rakus K, Ronsmans M, Vanderplasschen A. Behavioral fever in ectothermic vertebrates. Dev Comp Immunol. 2017;66:84-91. doi:10.1016/j.dci.2016.06.027 


\section{Publish your work in this journal}

The Journal of Experimental Pharmacology is an international, peerreviewed, open access journal publishing original research, reports, reviews and commentaries on all areas of laboratory and experimental pharmacology. The manuscript management system is completely

online and includes a very quick and fair peer-review system. Visit http://www.dovepress.com/testimonials.php to read real quotes from published authors.

Submit your manuscript here: https://www.dovepress.com/journal-of-experimental-pharmacology-journal 